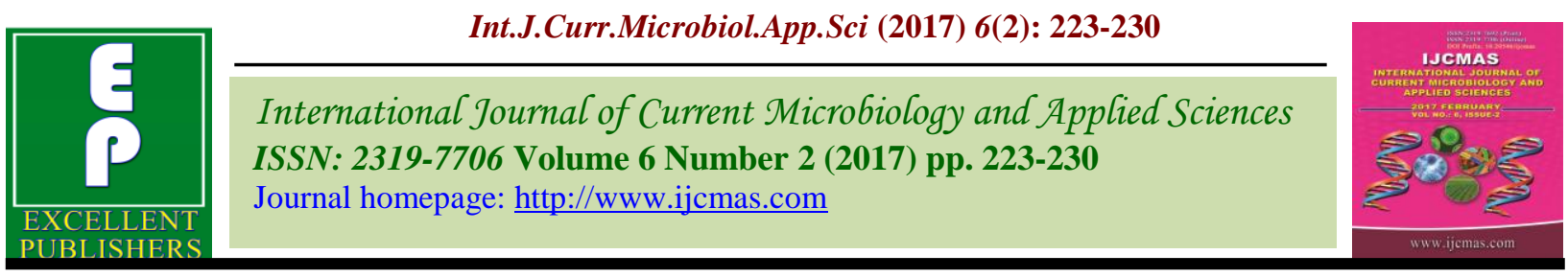

Original Research Article

http://dx.doi.org/10.20546/ijcmas.2017.602.029

\title{
Identification and Characterization of Methicillin-Resistant Staphylococcus aureus Isolated from Bovine Mastitis
}

\author{
A.G. Bhagat*, H.N. Kher, A.I. Dadawala, H.C. Chauhan, B.K. Patel, \\ M.D. Shrimali and B.S. Chandel
}
Department of Veterinary Microbiology, College of Veterinary Science and
Animal Husbandry Sardarkrushinagar Dantiwada Agricultural University,
Sardarkrushinagar- 385 506, Gujarat, India
*Corresponding author

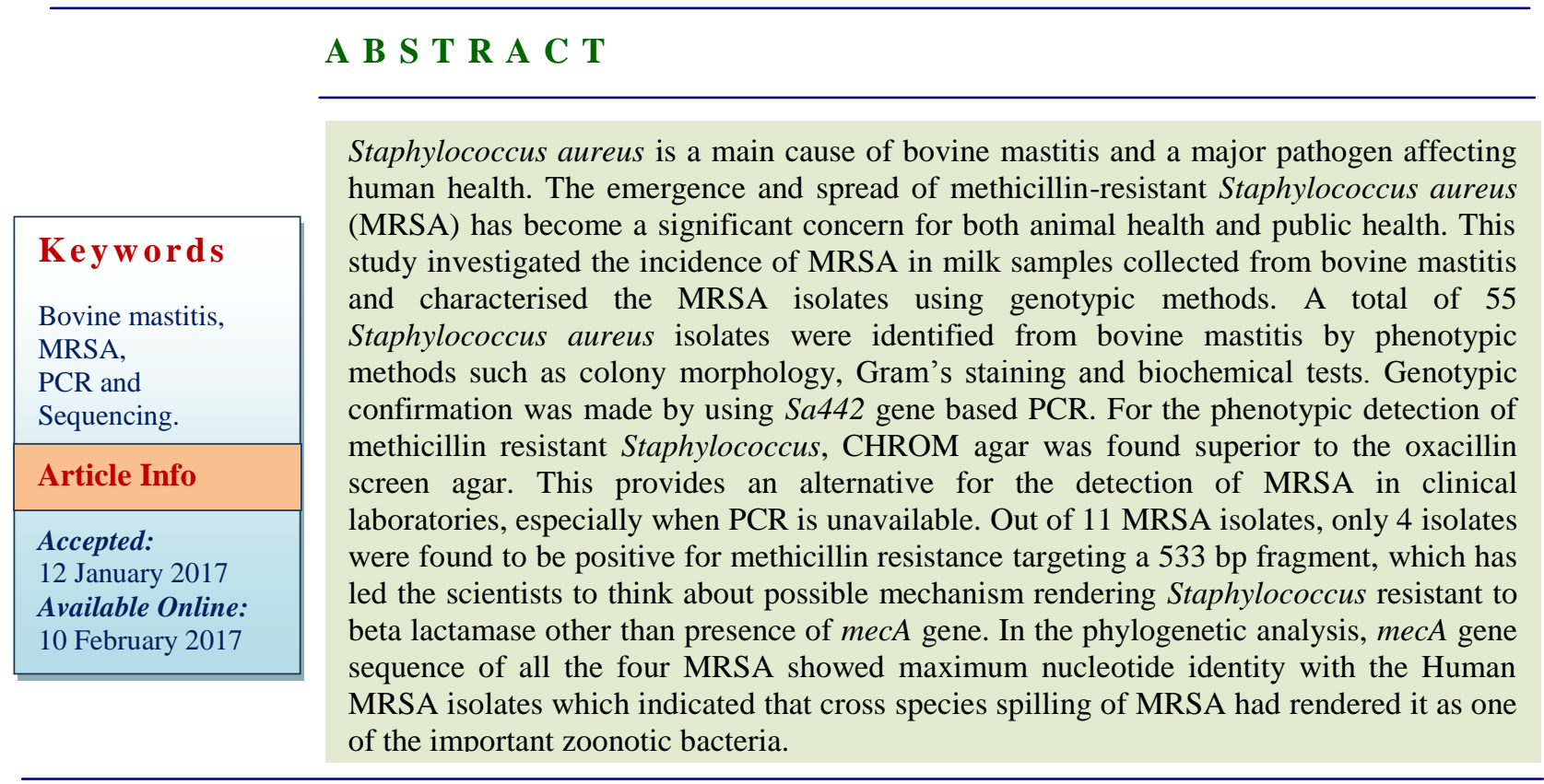

\section{Introduction}

Mastitis in dairy animals is considered as one of the most important economic diseases resulting into huge economic loss to the country. In India, the overall economic loss due to mastitis is estimated to be Rs. 7165.51 crores (Bansal and Gupta, 2009). A plethora of bacteria has been isolated and designated as etiological agents of mastitis in dairy animals, but Staphylococcus aureus has been reported as the major pathogen that produces both sub-clinical and clinical intramammary infection (Sharma and Sindhu, 2007).
Staphylococci have a reputation of rapidly developing resistance to virtually any antibiotic drugs (Pantosti et al., 2007 and Lentino et al., 2008). The resistance of Staphylococcus aureus to antimicrobial agents has been extensively documented and it contributed significantly to the treatment failure (Sudhakar et al., 2009 and Kumar et al., 2010). Resistance to methicillin that indicates resistance to all beta-lactam agents was first reported in 1961, the date that marks the appearance of Methicillin-resistant 
Staphylococcus aureus. For many years, Methicillin resistant Staphylococcus aureus was considered only a human pathogen, until a report of a MRSA infection in a dairy cow suffered in 1972 (Devriese et al., 1972). Methicillin resistance is due to the acquisition of the mecA gene, that encodes a new protein designated PBP2a, belonging to a family of enzymes necessary in building the bacterial cell wall. PBP2a has a very low affinity for $\beta$ lactam antibiotics and confers resistance to methicillin and the other $\beta$-lactams (Pantosti et al., 2007).

The mecA gene is located on a mobile genetic element, named staphylococcal cassette chromosome mec (SCC mec) inserted in the Staphylococcus chromosome up stream to the orf X (Katayama et al., 2000).

The transmission of bovine MRSA to humans is possible and may contribute to outbreaks in human populations (Lee, 2003). Hence, it is necessary to determine the endemic strains of Staphylococcus in dairy animals which are highly pathogenic and methicillin-resistant. Sequencing of mecA gene of MRS is used to determine the genetic relationship between the animal and human isolates of MRS, to understand the role of animals as reservoir for MRS infection to humans and vice-versa (Vishnupriya et al., 2014).

The objective of the present study was to gain insight into the presence of methicillinresistant Staphylococcus aureus (MRSA) among Staphylococcus aureus isolated from bovine mastitis in Gujarat. The MRSA found were characterized by sequencing in order to gain more insight in their epidemiology. In addition, we compared sequence of MRSA isolated from animals with the sequence of humans MRSA isolates available on Genebank in order to investigate whether these strains are related and to examine their zoonotic potential.

\section{Materials and Methods}

Isolation and Identification of Staphylococcus aureus

A total of 165 milk samples from suspected cases of clinical mastitis in cows $(n=94)$ and buffaloes $(n=71)$ belonging to North Gujarat were collected aseptically in sterilised vials. In addition, a total of 34 samples were detected positive for SCM, which included 25 samples from cows and 9 samples from buffaloes were also collected aseptically. Milk samples were collected after cleaning the teats, discarding a few streams of milk and scrubbing the teat ends with cotton balls moistened with 70\% alcohol. In all, 199 individual quarter milk samples were obtained. Milk samples were inoculated on the plates of Nutrient Agar by spreading heavy inoculums of thoroughly mixed milk. The plates were incubated at $37^{\circ} \mathrm{C}$ for 24 hours. Thereafter, colonies showing golden yellow pigmented or white colony colour indicative of presumptive Staphylococcus aureus were transferred to Mannitol Salt Agar which is considered as selective medium for Staphylococcus. The colonies forming yellow colouration indicative of mannitol fermentation were assumed to be $S$. aureus. Further identification of these presumptive staphylococcal colonies was first based on conventional methods including Gram stain staining, colony morphology, catalase test, oxidase test and coagulase test with rabbit plasma.

\section{Genotypic confirmation of Staphylococcus aureus}

All the probable Staphylococcus aureus isolates were subjected for Species specific sa442 gene based PCR. The primers used were sa442 F AATCTTTGTCGG TACACG ATATTCTTCACG and sa442 R CGTAATG AGATTTCAGTAGATAATACAACA (Martineau et al., 1998). 
Phenotypic identification of methicillin resistant Staphylococcus isolates

\section{Oxacillin screen agar test}

A bacterial inoculum of each strain was made and turbidity was adjusted to $0.5 \mathrm{McF}$ arland. One drop of this suspension was inoculated on Mueller-Hinton agar containing 4.00 per cent of $\mathrm{NaCl}$ and $6 \mu \mathrm{g}$ of oxacillin $\mathrm{ml}^{-1}$ (HiMedia). Plates were incubated at $35^{\circ} \mathrm{C}$ for 24 hrs. The strain showing growth on the plate containing oxacillin was considered to be resistant to methicillin.

\section{CHROM agar}

CHROMagar (Hi-Media) is a new chromogenic medium for the identification of MRSA. For each strain, a bacterial suspension adjusted to 0.5 McFarland was used. Subsequently, a swab was dipped in the suspension and streaked onto a CHROMagar plate. The growth of any pink to mauve colony was considered to be positive, indicating MRSA.

\section{Detection of mecA}

The presence of the mecA gene was detected by PCR as described before (Fluit et al., 2001). MecA DNA was amplified with the primers mecA $F$ AAAATCGATGGTAAAG GTTGGC and mecA R AGTTCTGCAGT AC CGGATTTGC. Samples were subjected to 35 cycles consisting of $30 \mathrm{sec}$. at $94^{\circ} \mathrm{C}, 30 \mathrm{sec}$. at $55^{\circ} \mathrm{C}$ an annealing temperature and $1 \mathrm{~min}$ at $72^{\circ} \mathrm{C}$ in a thermocycler. The PCR product was visualized on a $1.5 \%$ agarose gel using ethidium bromide and a UV transilluminator.

Sequencing and phylogenetic analysis of Methicillin resistant Staphylococcus isolates

Genomic DNA was extracted and then submitted for partial sequencing of mecA gene at the Eurofins Genomics (Bangalore, India). The DNA sequencing was performed by using Applied Biosystems BigDye ${ }^{\circledR}$ Terminator v3.1 and v1.1 Cycle Sequencing Kits with Applied Biosystems 3730xl 96 capillary DNA Analysers instrument.

The specificity of the sequences obtained, the nucleotide variations and amino acid variations with respect to the mecA gene sequence of MRSA strains were determined using BLAST (Basic Local Alignment Search Tool) (http://blast.ncbi.nlm.nih.gov/Blast.cgi). Phylogenetic analysis was conducted for the four MRSA isolates (SKN-4, SKN-5, SKN-6 and SKN-7) along with Human MRSA isolates from Tamil Nadu (KC243783), Pondicherry (JF710611), Portugal (JF946505) and Denmark (KF169798) retrieved from the Gene Bank.

Nucleotide sequences were aligned using the Clustal w alogarithm implemented in the Mega 6.06 program package (Center for Evolutionary Medicine and Informatics, the Biodesign Institute, USA) and Neighbor Joining tree (NJ tree) was constructed.

\section{Results and Discussion}

A total of 55 Staphylococcus aureus isolates were recovered from bovine mastitis. In Gram's stained culture smears under microscope, all the 55 isolates revealed spherical and irregular clusters like bunch of grapes. Bio-chemical characterization revealed that $100.00,100.00$ and 89.09 per cent isolates were Catalase positive, Oxidase negative and coagulase positive, respectively.

\section{Genotypic confirmation of Staphylococcus aureus}

All the 55 isolates yielded 108 bp amplicon in sa442 gene amplification which confirmed them as a Staphylococcus aureus (Fig. 1) 


\section{Phenotypic identification of MRSA isolates}

The conventional detection assays are simple and relatively cheap methods for detecting methicillin resistance. Out of 55 Staphylococcus aureus isolates, 7 and 11 isolates were detected as methicillin resistant by Oxacillin screen agar and CHROM agar, respectively. Among the two methods used for detection of methicillin resistant isolates, the sensitivity of CHROM agar and oxacillin screen agar methods in comparison to genotypic method was 100.00 and 71.42 57.14 per cent, respectively. Thus, CHROM agar was found superior to the oxacillin screen agar method.

Table.1 Per cent Nucleotide Identity in MRSA Isolates

\begin{tabular}{|c|c|c|c|c|c|c|c|c|}
\hline & KF169798 & JF946505 & SKN-5 & SKN-7 & KC243783 & JF710611 & SKN-4 & SKN-6 \\
\hline KF169798 & 100.00 & 42.99 & 45.31 & 47.03 & 48.39 & 48.44 & 44.44 & 46.46 \\
\hline JF946505 & & 100.00 & 54.64 & 58.73 & 57.17 & 57.53 & 56.08 & 56.88 \\
\hline SKN5 & & & 100.00 & 91.80 & 86.27 & 85.89 & 86.92 & 92.73 \\
\hline SKN7 & & & & 100.00 & 96.10 & 95.70 & 94.35 & 95.48 \\
\hline KC243783 & & & & & 100.00 & 99.81 & 86.63 & 94.90 \\
\hline JF710611 & & & & & & 100.00 & 86.27 & 94.50 \\
\hline SKN4 & & & & & & & 100.00 & 95.49 \\
\hline SKN6 & & & & & & & & 100.00 \\
\hline
\end{tabular}

Fig.1 \& 2
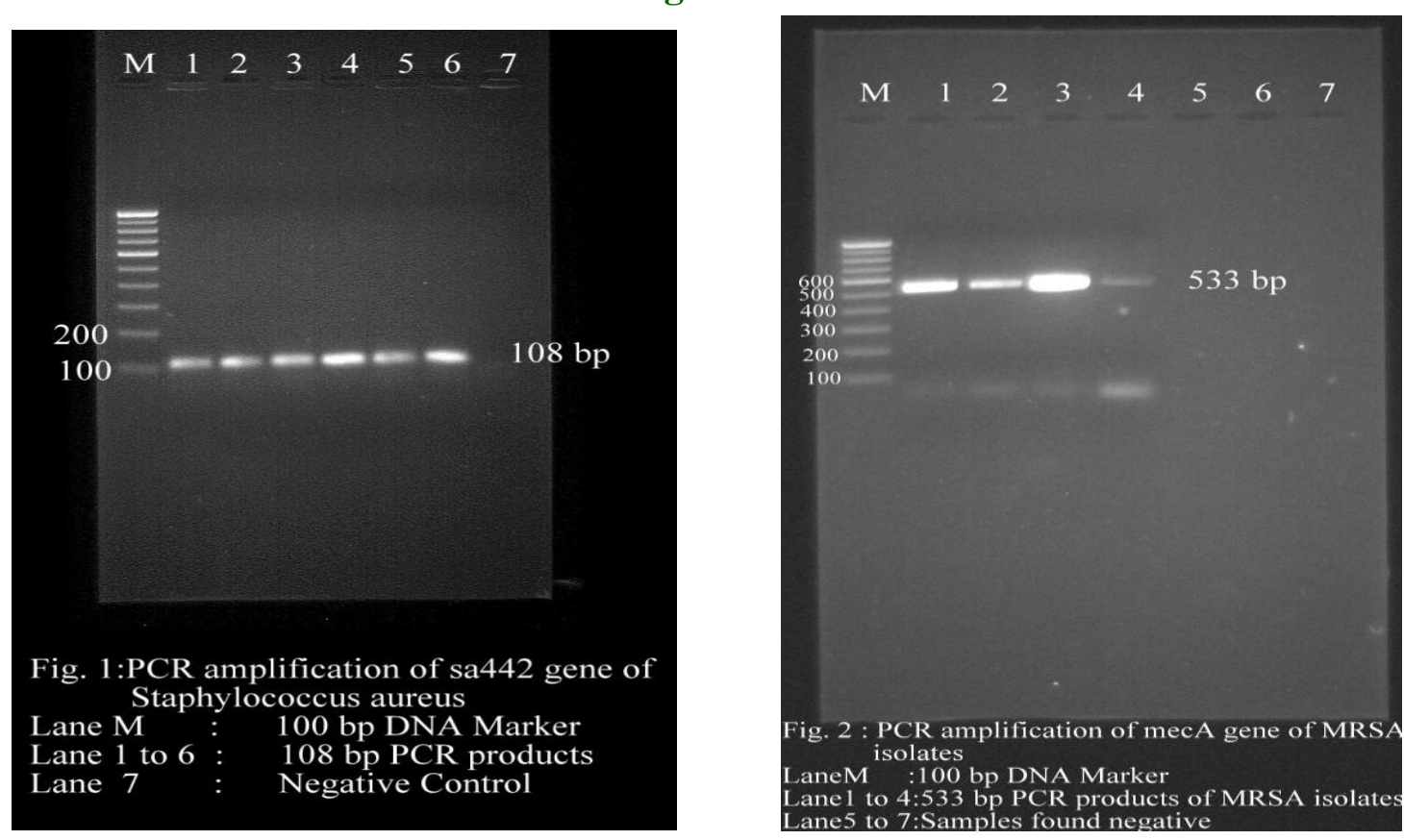
Fig.3

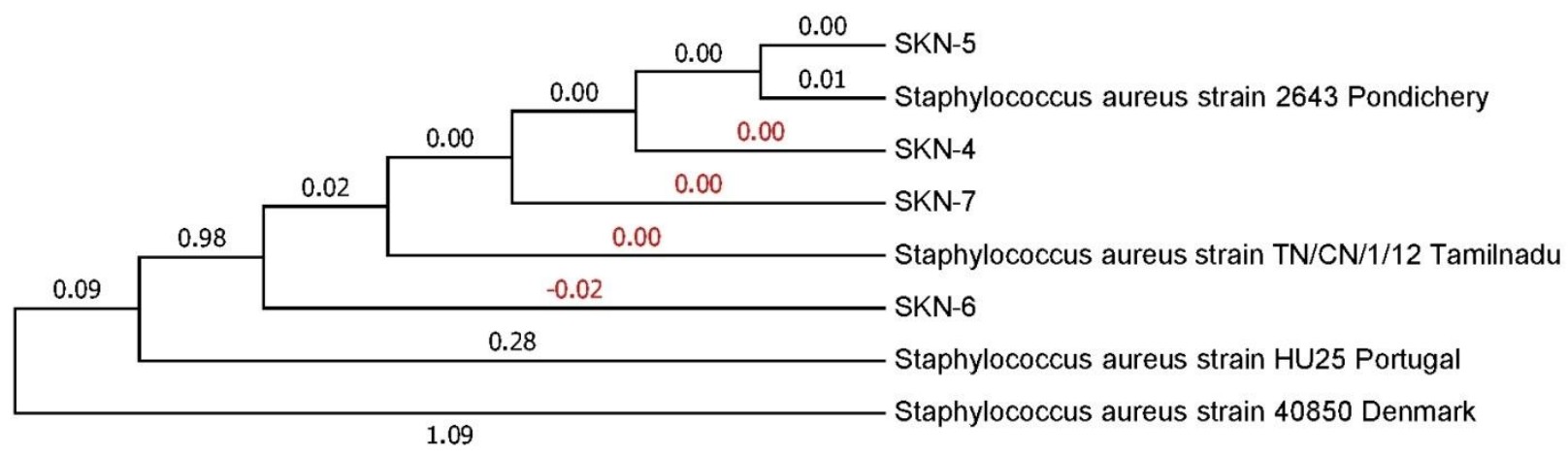

Similar findings were also observed by Taguchi et al., (2004) and Karthy et al., (2009). This provides an alternative for the detection of MRSA in clinical laboratories, especially when PCR is unavailable.

Higher sensitivity of CHROMagar in this study might be attributed to the fact that CHROMagar with cefoxitin supplement was potent inducer of the mecA gene; this could explain why heterogeneous MRS populations that variably express the $m e c A$ gene are better detected by CHROMagar with cefoxitin than medium with oxacillin, which is a weak inductor of PBP2a production. Furthermore, it was less affected by the hyper production of penicillinases, it required no special incubation temperature as was required when the testing was done with oxacillin screen agar (Mallick and Basak, 2010 and Mathews et al., 2010).

\section{Genotypic identification of MRSA isolates}

Accurate detection of methicillin resistance in Staphylococcus aureus by routine methods is difficult due to the presence of two subpopulation of Staphylococcus aureus (i.e., one susceptible and other resistant), which may coexist within a culture. All the cells in culture may carry the genetic information for resistance, but a small numbers can express this kind of resistance in routine susceptibility testing performed in the laboratory. This phenomenon is termed as heterogeneous resistance and occurs in Staphylococcus aureus resistant to penicillinase stable penicillin such as methicillin and oxacillin (Cavassini et al., 1999). The basis of most methicillin resistance is the production of an additional penicillin-binding protein, $\mathrm{PBP} 2$ ' or PBP2a, mediated by the mecA gene which is an additional gene found in methicillin resistant Staphylococcus and with no allelic equivalent in methicillin susceptible Staphylococcus. Therefore, the earlier worker (Krishnan et al., 2002 and Brown et al., 2005) considered test based on detection of mecA gene using PCR as rapid, accurate, commercially available and the gold standard for the detection of methicillin resistant Staphylococcus and found even correctly identify the most heterogeneous and borderline strains. However, in the present study, 11 phenotypical MRSA isolates from bovine mastitis were analysed by PCR for the presence of mecA gene. The mecA gene was detected only in 4 of 11 . Thus, seven Staphylococcus aureus isolates phenotypically resistant to methicillin in this study did not carry mecA gene. This type of discrepancy in correlation between the mecA gene and phenotypically methicillin resistance has been reported earlier by Schnellmann et al., (2006) and Moon et al., (2007). The possible reasons for this type of discrepancy 
are that the isolates appeared to show poor expression of mecA genes or production of methicillinase (alteration of PBP subtypes) or seem to overproducing $\beta$-lactamase. The phenotypic expression of resistance could vary due to growth conditions which are also involved in the expression of methicillin resistance (Zmantar et al., 2008; Turutoglu et al., 2009 and Turkylmaz et al., 2010).

\section{Sequencing and phylogenetic analysis of MRSA isolates}

There are increasing reports on MRSA infection or colonization in animals and their zoonotic potential (vanDuijkeren et al., 2004; Malik et al., 2006; Schnellmann et al., 2006; Weese et al., 2006 and Kaszanyitzky et al., 2007). However, a few veterinary reports have compared the mecA gene from animal isolates with human MRS strains (Malik et al., 2006 and Schnellmann et al., 2006). Hence, the present study was also intended for comparison of the mecA gene from animal MRSA isolates with the human MRSA strains available on Gene Bank.

The same results were also stated for the presence of mecA genes from bovine mastitis (Turutoglu et al., 2009 and Vishnupuriya et al., 2014) dogs, cats (Malik et al., 2006) and horses (Schnellmann et al., 2006). Based on the results from the present study and the other studies (vanDuijkeren et al., 2004 and Malik et al., 2006), it can be construed that these isolates might have originally come from humans, considering that the methicillin resistance among human Staphylococcus isolates is common. However, in the recent years, it has been suggested that humans in close contact with MRSA infected or colonized animals may be infected (Weese et al., 2006 and Kaszanyitzky et al., 2007) or human infections may be originated by consumption of food-stuff made from infected animals (Lee, 2003).
In conclusion, mecA-positive $S$, aureus isolated from animals in Gujarat, but their prevalence appears to be low. Both phenotypic and genotypic analysis showed that the four MRSA isolates of bovine origin were indistinguishable. It could be concluded that the bovine MRSA strains described in this study were genetically related to the human strain, which may indicates the transmission between bovine and humans. Periodic surveillance for antimicrobial resistance patterns of MRSA isolated from dairy cows with mastitis could be an important measure in detecting the emergence and spreading of such resistance.

\section{Acknowledgement}

The authors are thankful to the Ministry of Minority Affairs, UGC, for the financial assistance in the form of Maulana Azad National Fellowship and to the Dean,College of Veterinary Science and Animal Husbandry, Sardar krushinagar for providing the necessary facilities.

\section{References}

Anthony, A.A. and Anthony, I.O. 2014. Species diversity and antibiotic resistance properties of Staphylococcus of farm animal origin in Nkonkobe Municipality, South Africa. Folia Microbiol., 59:133140.

Bansal, B.K. and Gupta, D.K. 2009. Economic analysis of bovine mastitis in India and Punjab.

Brown, D.F., Edwards, D.I., Hawkey, P.M., Morrison, D., Ridgway, G.L. and Towner, K.J. 2005. Guidelines for the laboratory diagnosis and susceptibility testing of methicillin resistant Staphylococcus aureus (MRSA). J. Antimicrob. Chemother., 56: 1000-18.

Cavassini, M., Wenger, A., Jaton, K., Blanc, D.S. and Bille, J. 1999. Evaluation of MRSA screen, a simple anti-PBP2a slide 
latex agglutination kit for rapid detection of methicillin resistance in Staphylococcus aureus. J. Clin. Microbiol., 37: 1591-1594.

Devriese, L.A., Van Damme, L.R. and Fameree, L. 1972. Methicillin-(cloxacillin)-resistant Staphylococcus aureus strains isolated from bovine mastitis cases. Zentralbl. Veterinar. Med., 19: 598-605.

Kalorey, D.R., Shanmugam, Y., Kurkure, N.V., Chousalkar, K.K. and Barbuddhe, S.B. 2007. PCR-based detection of genes encoding virulence determinants in Staphylococcus aureus from bovine subclinical mastitis cases. J. Vet. Sci., 8(2): 151-154.

Karthy, E.S., Ranjitha, P. and Mohankumar, A. 2009. Performance of CHROMagar and Oxacillin Resistant Screening Agar Base media for detection of Methicillin Resistant Staphylococcus aureus (MRSA) from Chronic Wound. Modern App. Sci., 3(5): 51-56.

Kaszanyitzky, E.J., Janosi, S., Somogyi, P., Dan, A., van der Graaf-van Bloois, L., van Duijkeren, E. and Wagenaar, J.A. 2007. MRSA transmission between cows and humans. Emer. Infect. Dis., 13(4): 630-632.

Katayama, Y., Ito, T. and Hiramatsu, K. 2000. A New Class of Genetic Element, Staphylococcus Cassette Chromosome mecA Encodes Methicillin Resistance in Staphylococcus aureus. Antimicrob. Agents Chemother., 44(6): 1549-1555.

Krishnan, P.U., Miles, K. and Shetty, N. 2002. Detection of methicillin and mupirocin resistance in Staphylococcus aureus isolates using conventional and molecular methods: A descriptive study from a burns unit with high prevalence of MRSA. J. Clin. Pathol., 55(10):745-748.

Kumar, R., Yadav, B.R. and Singh, R.S. 2010. Genetic determinants of antibiotic resistance in aureusisolates from milk of mastitic crossbred cattle. Curr. Microbiol., 60: 379-386.

Lee, J.H. 2003. Methicillin (Oxacillin)-resistant Staphylococcus aureus strains isolated from major food animals and their potential transmission to humans. Appl. Environ. Microbiol., 69: 6489-6494.

Lentino, J.R., Narita, M. and Yu, V.L. 2008. New antimicrobial agents as therapy for resistant gram-positive cocci. European J. Clin. Microbiol. Infect. Dis., 27: 3-15.

Malik, S., Peng, H. and Barton, M.D. 2006. Partial nucleotide sequencing of the mecA gene of Staphylococcus aureus isolates from Cats and Dogs. J. Clin. Microbiol., 44(2) :413-416.

Mallick, S.K. and Basak, S. 2010. MRSA - too many hurdles to overcome; a study from central India. Trop. Doct., 40: 108-110.

Martineau, F., Picard, F.J., Roy, P.H., Ouellette, M. and Bergeron, M.G. 1998.Speciesspecific and ubiquitous-DNA-based assays for rapid identification of Staphylococcus aureus. J. Clin. Microbiol., 36: 618-623.

Mathews, A.A., Thomas, M., Appalaraju, B. and Jayalakshmi, J. 2010. Evaluation and comparison of tests to detect methicillin resistant Staphylococcus aureus. Indian J. Pathol. Microbiol., 53(1): 79-82.

Momtaz, H., Rahimi, E. and Tajbakhsh, E. 2010. Detection of some virulence factors in Staphylococcus aureus isolated from clinical and sub-clinical bovine mastitis in Iran. African J. Biotech., 9(25): 37533758 .

Moon, J.S., Lee, A.R., Kang, H.M., Lee, E.S., Joo, Y.S., Park, Y.H., Kim, M.N. and Koo, H.C. 2007. Antibiogram and Coagulase diversity in Staphylococcal Enterotoxin producing Staphylococcus aureus from bovine mastitis. J. Dairy Sci., 90: 1716-1724.

Pantosti, A., Sanchini, A. and Monaco, M. 2007. Mechanisms of antibiotic resistance in Staphylococcus aureus. Future Microbiol., 2 : 323-334.

Rusenova, N., Gebreyes, W., Koleva, M., Mitev, J., Penev, T., Vasilev, N. and Miteva, T. 2013. Comparison of three methods for routine detection of Staphylococcus aureus isolated from 
bovine mastitis. Kafkas Univ. Vet.Fak.Derg., 19(4): 709-712.

Schnellmann, C., Gerber, V., Rossano, A., Jaquier, V., Panchaud, Y., Doherr, M.G., Thomann, A., Straub, R. and Perreten, V. 2006. Presence of new mecA and $\mathrm{mph}(\mathrm{C})$ variants conferring antibiotic resistance in Staphylococcus spp. isolated from the skin of horses before and after clinic admission. J. Clin. Microbiol., 44: 44444454.

Sentitula, Yadav, B.R. and Kumar R. 2012.Incidence of Staphylococci and Streptococci during winter in mastitic milk of Sahiwal cows and Murrah buffaloes. Indian J. Microbiol., 52(2): 153-159.

Sharma, A. and Sindhu, N. 2007. Occurrence of clinical and sub-clinical mastitis in buffaloes in state of Haryana. Italian $J$. Anim. Sci., 6(2): 965-967.

Taguchi, H., Kaneko, T., Onozaki, M., Kubo, R. and Kamiya S. 2004.Evaluation of a new Chromogenic medium for isolation of MRSA. J. Japanese Assoc. Infect. Dis., 78: 54-58.

Turkyilmaz, S., Tekbyk, S., Oryasin, E. and Bozdogan, B. 2010. Molecular epidemiology and antimicrobial resistance mechanisms of methicillin resistant Staphylococcus aureus isolated from bovine milk. Zoonoses Pub. Hlth., 57: 197-203.
Turutoglu, H., Hasoksuz, M., Ozturk, D., Yildirim, M. and Sagnak, S. 2009. Methicillin and aminoglycoside resistance in Staphylococcus aureus isolates from bovine mastitis and sequence analysis of their mecA genes. Vet. Res. Commun., 33: 945-956.

Van Duijkeren, E., Box, A.T.A., Heck, M.E.O.C., Wannet, W.J.B. and Fluit, A.C. 2004. Methicillin resistant staphylococci isolated from animals. Vet. Microbiol., 103: 91-97.

Vishnupriya, S., Antony, P.X., Mukhopadhyay, H.K., Pillai, R.M., Thanislass, J., VivekSrinivas, V.M. and Sumanth Kumar, R. 2014. Methicillin resistant Staphylococci associated with bovine mastitis and their zoonotic importance. Vet. World, 7(6): 422-427.

Weese, J., Caldwell, F., Willey, B., Kreiswirth, B., McGeer, A., Rousseau, J. and Low, D. 2006. An outbreak of methicillin resistant Staphylococcus aureus skin infections resulting from horse to human transmission in a veterinary hospital. Vet. Microbiol., 114: 160-164.

Zmantar, T., Chaieb, K., Ben Abdallah, F., Ben Kahla, N.A., Ben Hassen, A., Mahdouani, K. and Bakhrouf, A. 2008. Multiplex PCR detection of the antibiotic resistance genes in Staphylococcus aureus strains isolated from auricular infections. Folia Microbiol., 53(4): 357-362.

\section{How to cite this article:}

Bhagat, A.G., H.N. Kher, A.I. Dadawala, H.C. Chauhan and Chandel, B.S. 2017. Identification and Characterization of Methicillin-Resistant Staphylococcus aureus Isolated from Bovine Mastitis. Int.J.Curr.Microbiol.App.Sci. 6(2): 223-230.

doi: http://dx.doi.org/10.20546/ijcmas.2017.602.029 